\title{
Influence of Testing Temperature on the Corrosion Behavior of API 5L X70 Pipeline Steel
}

\author{
Carlos Antonio Vieira de Almeida Machado ${ }^{1}$, Renato Altobelli Antunes ${ }^{1}$, Elisabete Jorge Pessine ${ }^{2}$ and Olandir \\ Vercino Correa ${ }^{2}$ \\ 1. Centro de Engenharia, Modelagem e Ciências Sociais Aplicadas (CECS),Universidade Federal do ABC, Santo André 09210-580, \\ Brazil
}

2. Centro de Ciência e Tecnologia de Materiais (CCTM), Instituto de Pesquisas Energéticas e Nucleares(IPEN/CNEN-SP), Cidade Universitária, São Paulo 05508-000, Brazil

Received: March 11, 2014 / Accepted: April 01, 2014 / Published: June 25, 2014.

\begin{abstract}
It is known that localized corrosion attack takes a preponderant role in the onset of stress corrosion cracking of pipeline steels in high $\mathrm{pH}$ conditions. Carbonate/bicarbonate solutions can be employed to study the localized corrosion behavior of these materials. In addition to the presence of chloride ions in the electrolyte, the solution temperature is also of prime importance to the onset of pitting corrosion. The aim of this work is to evaluate the influence of the testing temperature on the corrosion behavior of the API 5L $\mathrm{X} 70$ pipeline steel which is a standard material for gas pipelines in Brazil. Samples were exposed to a solution consisting of $\mathrm{Na}_{2} \mathrm{CO}_{3}$, $\mathrm{NaHCO}_{3}$ and $\mathrm{NaCl}$ at three different temperatures: RT (room temperature), $40{ }^{\circ} \mathrm{C}$ and $60^{\circ} \mathrm{C}$. The corrosion morphology was observed using SEM (scanning electron microscopy). The results showed that pitting corrosion became facilitated when the steel was immersed at higher temperatures.
\end{abstract}

Key words: API 50 X70, pipeline steel, corrosion, temperature.

\section{Introduction}

API 5L X70 is a pipeline steel currently used in Brazil to transportation of natural gas and oil. This type of structure is designed to ensure that failures resulting from high pressure, thermal effects and environmental degradation are prevented [1]. Most parts of oil and gas sources in the world are located in remote areas and demand transportation by pipelines in order to reach their major markets [2]. The environments where these pipelines are installed are considered aggressive to the API steels due to the presence of species such as $\mathrm{Cl}^{-}$, $\mathrm{NCO}_{3}{ }^{-}, \mathrm{CO}_{2}$ and $\mathrm{H}_{2} \mathrm{~S}$ [3]. SCC (stress corrosion cracking) is a serious threat to the safe operation of pipeline steels [4]. Several authors studied the SCC mechanisms of pipeline steels in different environments [5, 6]. Most

Corresponding author: Renato Altobelli Antunes, materials engineer, Ph.D., research fields: corrosion science and protective coatings. E-mail: renato.antunes@ufabc.edu.br. failures due to SCC of API steels are reported to occur under a high pH (approximately 9.5) condition which is associated with a concentrated solution consisting of carbonate/bicarbonate [7, 8]. A passive oxide layer can develop when the steel is exposed to this condition [9]. Chloride ions are reported to lead to the breakdown of the passive layer, forming corrosion pits. Pitting corrosion is considered as the first step of the SCC mechanism of pipeline steels [10]. In this context, it is imperative to investigate the pitting corrosion behavior of pipeline steels in order to guarantee a safer operation. Few works have been devoted to study the effect of temperature on the pitting corrosion resistance of pipeline steels. Nazari et al. [11] showed that the nature of the oxide layer formed on the surface of the X70 pipeline steel was strongly affected by the testing temperature. The aim of this work is to investigate the effect of the test temperature on the corrosion behavior 
of the API 5L X70 steel immersed in carbonate/bicarbonate solutions with addition of $\mathrm{NaCl}$. The electrochemical evaluation was performed based on electrochemical impedance spectroscopy measurements and potentiodynamic polarization curves. The onset of pitting corrosion at different testing temperatures was assessed. This paper is organized as follows: Section 2 describes the experimental procedure; Section 3 presents results and discussion; and Section 4 gives conclusions.

\section{Experimental Details}

\subsection{Material}

The material used in this work was a hot rolled API 5L X70 steel plate kindly provided by USIMINAS whose chemical composition is shown in Table 1.

\subsection{Electrochemical Tests}

The electrochemical tests were performed in an electrolyte which was comprised of $0.05 \mathrm{M} \mathrm{Na}_{2} \mathrm{CO}_{3}$, $0.1 \mathrm{M} \mathrm{NaHCO}_{3}$ and $0.1 \mathrm{M} \mathrm{NaCl}$ at three different temperatures: $40^{\circ} \mathrm{C}$ and $60^{\circ} \mathrm{C}$. The specimens were cut in rectangular dimensions, leaving an approximate area of $1 \mathrm{~cm}^{2}$ to be exposed to the electrolyte. All the electrochemical measurements were carried out using a potentiostat/galvanostat Autolab PGSTAT 100 equipped with a FRA module. A three-electrode cell arrangement was used, containing a $\mathrm{Pt}$ wire as the auxiliary electrode and a SCE (saturated calomel electrode) as reference; all potentials quoted in this paper are referred to this reference electrode. The specimen acting as working electrode was mounted in epoxy resin. The working electrode was ground with successive grade silicon carbide sandpaper up to 1,000 grit, polished with alumina paste $(1 \mu \mathrm{m})$, degreased with ethanol, rinsed with distilled water and dried in air.

EIS (electrochemical impedance spectroscopy) measurements were used to monitor the electrochemical behavior of the specimens during seven days of immersion. The data were collected under the OCP
Table 1 Results from traditional acquisition.

\begin{tabular}{ll}
\hline Element & Mass (\%) \\
\hline $\mathrm{C}$ & 0.12 \\
$\mathrm{Mn}$ & 1.490 \\
$\mathrm{~S}$ & 0.006 \\
$\mathrm{P}$ & 0.018 \\
$\mathrm{~V}$ & 0.020 \\
$\mathrm{Nb}$ & 0.017 \\
$\mathrm{Al}$ & 0.014 \\
$\mathrm{Fe}$ & Bal. \\
\hline
\end{tabular}

(open circuit potential) over a frequency range from $100 \mathrm{kHz}$ to $10 \mathrm{mHz}$ with an acquisition of 10 points/decade. The amplitude of the perturbation signal was $\pm 10 \mathrm{mV}$. Potentiodynamic polarization curves were obtained after seven days of immersion using a scan rate of $1 \mathrm{mV} \cdot \mathrm{s}^{-1}$ in the potential range from -300 $\mathrm{mV}$ vs. the OCP up to $1 \mathrm{~V}$.

\subsection{Corrosion Morphology}

The corrosion morphology of the tested specimens, emphasizing the presence of pits, was assessed using SEM (scanning electron microscopy) (Hitachi TM3000 tabletop).

\section{Results and Discussion}

\subsection{EIS Measurements}

EIS results are represented as Nyquist plots as shown in Fig. 1. The plots are referred to seven days of immersion in the electrolyte at different testing temperatures. Electrochemical AC techniques such as EIS have a low amplitude perturbation signal, making it attractive to study the corrosion processes of electrical conductors in aqueous electrolytes [12]. EIS is a powerful tool for investigating the mechanisms of electrochemical reactions. The Nyquist plots are characterized by a depressed semicircle spanning throughout the whole frequency range independently of the testing temperature. The highest frequencies are on the left whereas the lowest frequencies are on the right of the plots shown in Fig. 1. At a first glance, this indicates that the corrosion mechanism should be the same for the three different temperature conditions. In 
fact, Zhang et al. [13] stated that the capacitive semicircle which characterizes the Nyquist plots shown in Fig. 1 is typical of activation-controlled interfacial reactions.

In this regard, diffusion-controlled processes throughout the oxide layer formed on the surface of the specimen during immersion can be neglected. In spite of the similarity akin to the corrosion mechanisms suggested by the Nyquist plots, it is important to observe the relative impedance values obtained at each condition and, most importantly, the radius of the capacitive loops. It is well-known from the literature, that this radius is closely related to the corrosion resistance of the electrode surface [14]. Thus, the results suggest that the corrosion resistance was little affected when the testing temperature was raised from the RT to $40{ }^{\circ} \mathrm{C}$. However, by further increasing the temperature to $60{ }^{\circ} \mathrm{C}$ the radius of the semicircle was greatly depressed, indicating a significant loss of corrosion resistance. Recent studies by Tang et al. [15] and Xiang et al. [16] confirm that temperature seriously affects the corrosion rate of pipeline steels. The electrochemical reactions leading to reaction are favored at temperatures up to $70{ }^{\circ} \mathrm{C}$ or $90{ }^{\circ} \mathrm{C}$, accelerating corrosion. For higher temperatures, the corrosion rate can be depressed due to the formation of more protective oxide films. The results shown in Fig. 1 confirm the trend of increased corrosion kinetics for the temperatures evaluated in this work.

\subsection{Potentiodynamic Polarization Curves}

Potentiodynamic polarization curves of the API 5L X70 steel immersed for seven days at different temperatures in the electrolyte solution described in Section 2.2 are shown in Fig. 2. The electrochemical parameters determined from these curves are presented in Table 2. Corrosion potential $\left(E_{\text {corr }}\right)$, corrosion current density $\left(I_{c o r r}\right)$ and breakdown potential $\left(E_{b}\right)$ are reported.

The curves shown in Fig. 2 present a well-defined passive region independently of the testing temperature.

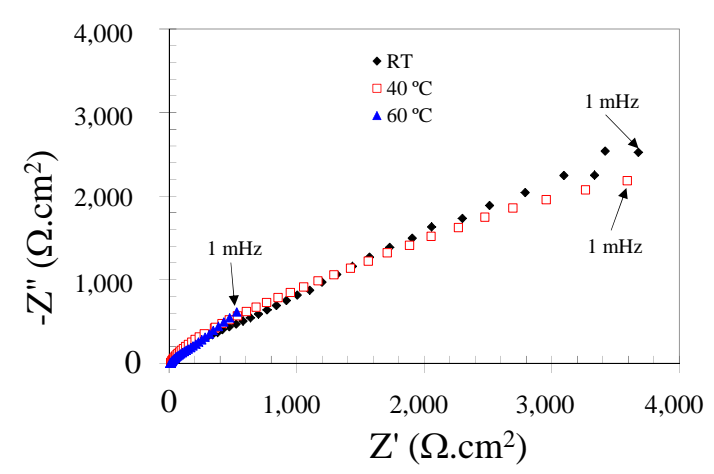

Fig. 1 Nyquist plots of the API 51 X70 steel immersion for 7 days at different testing temperatures.

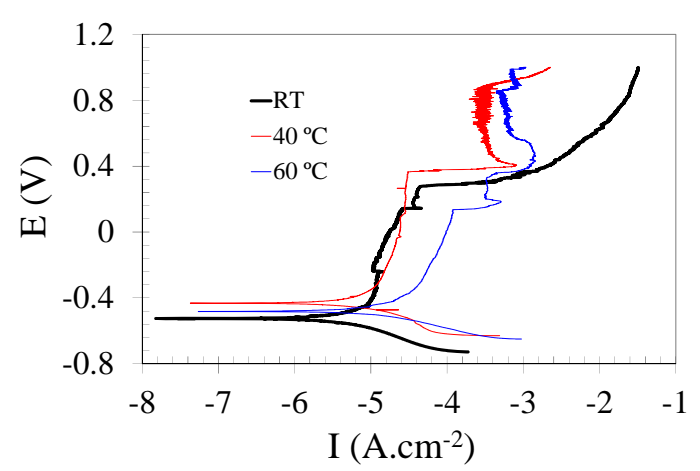

Fig. 2 Potentiodynamic polarization curves of the API 5L X70 steel immersed for seven days at different temperatures in the electrolyte solution described in Section 2.2.

Table 2 Electrochemical parameters determined from the potentiodynamic polarization curves shown in Fig. 2.

\begin{tabular}{|c|c|c|c|c|}
\hline Temperature & $E_{\text {corr }}(\mathrm{mV})$ & $\begin{array}{l}I_{\text {corr }} \\
\left(\mu \mathrm{A} \cdot \mathrm{cm}^{-2}\right)\end{array}$ & $E_{b}(\mathrm{mV})$ & $\begin{array}{l}\text { Passive } \\
\text { range (mV) }\end{array}$ \\
\hline $\mathrm{RT}$ & -0.53 & 2.18 & 0.27 & 0.80 \\
\hline $40{ }^{\circ} \mathrm{C}$ & -0.43 & 4.17 & 0.38 & 0.81 \\
\hline $60^{\circ} \mathrm{C}$ & -0.51 & 11.7 & 0.11 & 0.62 \\
\hline
\end{tabular}

The onset of pitting corrosion is evident from the sharp increase of the current density at the breakdown potentials $\left(E_{b}\right)$. In spite of the similarities between the curves especially in respect to the presence of a passive region, remarkable differences can be observed depending on the testing temperature. The passive currents for the room temperature condition are slightly lower than at $40{ }^{\circ} \mathrm{C}$ up to the breakdown potential as well as the value of $I_{\text {corr }}$, suggesting that the corrosion resistance of the API steel is higher at the lowest testing temperature. Nevertheless, the passive range is very similar for these conditions and the current densities 
associated with the specimens tested at $40{ }^{\circ} \mathrm{C}$ are also small, indicating that the corrosion properties of the API 5L X70 steel was little affected when the temperature was raised up to this level. This is in agreement with the EIS measurements as inferred from the Nyquist plots shown in Fig. 1.

For the tests performed at $60^{\circ} \mathrm{C}$, though, there was an evident reduction of the corrosion resistance. The onset of pitting corrosion occurred at a breakdown potential of only $0.11 \mathrm{~V}$ and the passive range was shortened to $0.62 \mathrm{~V}$. Thus, it is possible to affirm that the API 5L X70 steel became more prone to localized corrosion attack when the temperature reached $60^{\circ} \mathrm{C}$. Furthermore, the corrosion current density was almost three times higher at $60{ }^{\circ} \mathrm{C}$ when compared to that determined at $40{ }^{\circ} \mathrm{C}$ and more than five times higher than that obtained at the room temperature. This result points to an overall higher corrosion rate of the specimens tested at $60^{\circ} \mathrm{C}$.

\subsection{Corrosion Morphology}

According to Ref. [10], SCC of pipeline steels can be initiated in the bottom of a pit. The initial pitting mechanism is related to corrosion at metallurgical heterogeneities such as grain boundaries, non-metallic inclusions and interfaces between different phases. As observed in the potentiodynamic polarization curves shown in Fig. 2, the onset of pitting corrosion has been observed for the API 5L X70 steel independently of the testing temperature. Moreover, the resistance to pitting corrosion was found to decrease at $60{ }^{\circ} \mathrm{C}$. Hence, the propensity to SCC should accompany this temperature dependence. In order to share more light on this subject, the corrosion morphology of the steels was evaluated using SEM (Fig. 3).

The micrograph shown in Fig. 3a corresponds to the surface of a specimen tested at room temperature after potentiodynamic polarization. Fig. $3 b$ shows the same region at a higher magnification. The specimens tested at higher temperatures presented similar corrosion morphology but with increasing number of pits,

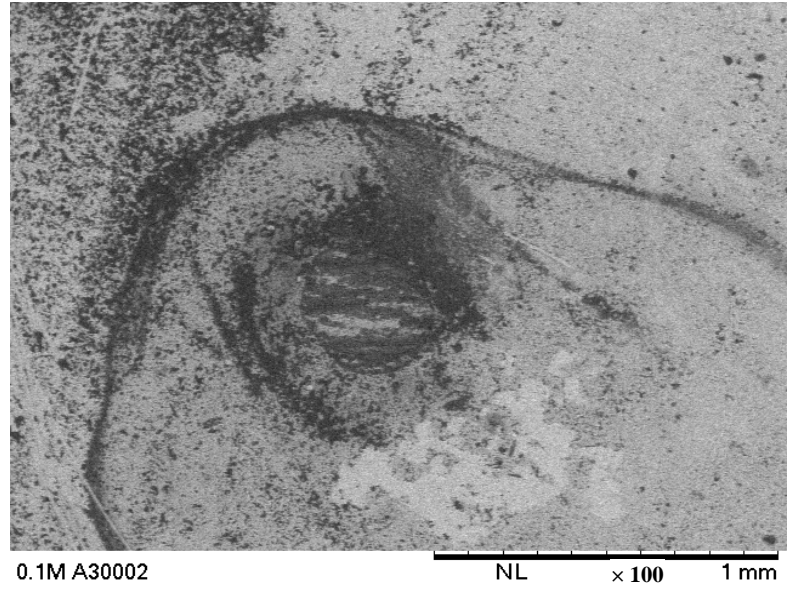

(a)

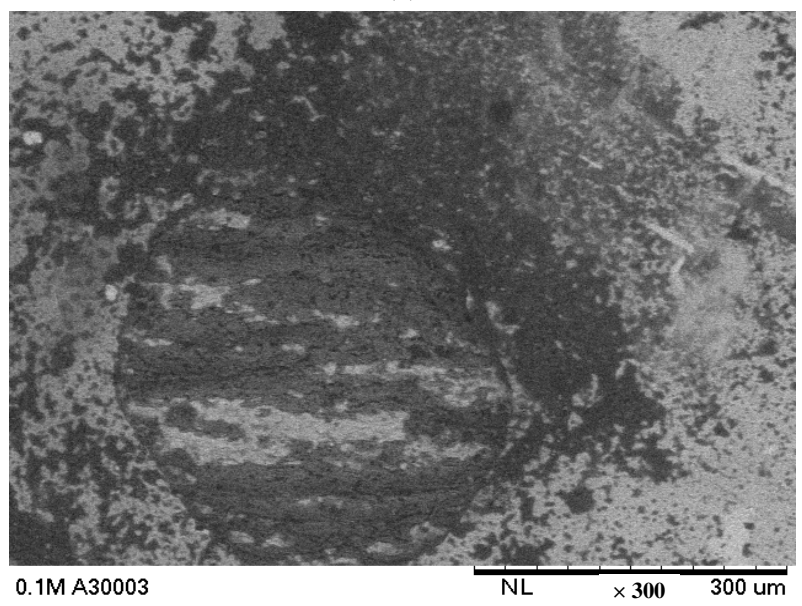

(b)

Fig. 3 SEM micrograph showing the presence of one shallow pit after potentiodynamic polarization of the API 5L X70 steel at room temperature. The micrograph on the right is referred to the same region on the left at a higher magnification.

especially those tested at $60{ }^{\circ} \mathrm{C}$. Shallow pits were observed. Van Boven et al. [10] showed that cracks originate from shallow pits during SCC of the X65 pipeline steel in simulated soil solution. In this regard, the results obtained in the present work point toward a dangerous corrosion activity of the X70 pipeline steel at $60{ }^{\circ} \mathrm{C}$. Even at RT, the presence of shallow pits is also observed.

\section{Conclusions}

The influence of the testing temperature on the corrosion behavior of the API 5L X70 pipeline steel in $0.05 \mathrm{M} \mathrm{Na}_{2} \mathrm{CO}_{3}, 0.1 \mathrm{M} \mathrm{NaHCO}_{3}$ and $0.1 \mathrm{M} \mathrm{NaCl}$ 
solution has been evaluated. The results showed that the steel was prone to pitting corrosion even at room temperature. When the temperature was raised to $40^{\circ} \mathrm{C}$ the corrosion properties were little affected. Nevertheless, for the tests performed at $60{ }^{\circ} \mathrm{C}$, there was a marked decrease of the corrosion resistance, in respect to either the overall corrosion rate expressed as the corrosion current density or the pitting corrosion resistance. In this context, based on the well-established relationship between the formation of pits and SCC of pipeline steels, the results reveal a more dangerous situation for the initiation of SCC at 60 ${ }^{\circ} \mathrm{C}$. Notwithstanding, pits have also been observed at lower temperatures.

\section{Acknowledgments}

Usiminas is acknowledged for kindly providing the API 5L X70 steel plate used in this work.

\section{References}

[1] F.J. Sánchez, B. Mishra, D.L. Olson, Magnetization effect on hydrogen absorption in high strength steels and its implications, Scripta Materialia 53 (2005) 1443-1448.

[2] S.H. Hashemi, Correction factors for safe performance of API X65 pipeline steel, International Journal of Pressure Vessels and Piping 86 (2009) 533-540.

[3] Z.Y. Liu, X.G. Li, C.W. Du, G.L. Zhai, Y.F. Cheng, Stress corrosion cracking behavior of X70 pile steel in an acidic soil environment, Corrosion Science 50 (2008) 2251-2257.

[4] Z. Liu, X. Li, Y. Zhang, C. Du, G. Zhai, Relationship between electrochemical characteristics and SCC of X70 pipeline steel in na acidic soil simulated solution, Acta Metallurgica Sinica 22 (2009) 58-64.

[5] A. Eslami, B Fang, R. Kania, B. Worthingham, J. Been, R. Eadie, et al., Stress corrosion cracking initiation under the disbanded coating of pipeline steel in near-neutral $\mathrm{pH}$ environment, Corrosion Science 52 (2010) 3750-3756.

[6] F.M. Song, Predicting the mechanisms and crack growth rates of pipelines undergoing stress corrosion cracking at high $\mathrm{pH}$, Corrosion Science 51 (2009) 2657-2674.

[7] M.C. Li, Y.F. Cheng, Corrosion of the stressed pipe steel in carbonate-bicarbonate solution studied by scanning localized electrochemical impedance spectroscopy, Electrochimica Acta 53 (2008) 2831-2836.

[8] S. Tang, Y.F. Cheng, Localized dissolution electrochemistry at surface irregularities of pipeline steel, Applied Surface Science 254 (2008) 5199-5205.

[9] R.N. Parkins, S. Zhou, The stress corrosion cracking of $\mathrm{C}-\mathrm{Mn}$ steel in $\mathrm{CO}_{2}-\mathrm{HCO}_{3}-\mathrm{CO}_{3}{ }^{2-}$ solutions: I: Stress corrosion data, Corrosion Science 39 (1997) 159-173.

[10] G. van Boven, W. Chen, R. Rogge, The role of residual stress in neutral $\mathrm{pH}$ stress corrosion cracking of pipeline steels. Part I: pitting and cracking occurrence, Acta Materialia 55 (2007) 29-42.

[11] M.H. Nazari, S.R. Allahkaram, M.B. Kermani, The effects of temperature and $\mathrm{pH}$ on the characteristics of corrosion product in $\mathrm{CO}_{2}$ corrosion of grade X70 steel, Materials and Design 31 (2010) 3559-3563.

[12] K. Jüttner, EIS (electrochemical impedance spectroscopy) of corrosion processes on inhomogeneous surfaces, Electrochimica Acta 35 (1990) 1501-1508.

[13] G.A. Zhang, Y.F. Cheng, Electrochemical corrosion of X65 pipe steel in oil/water emulsion, Corrosion Science 51 (2009) 901-907.

[14] R.A. Antunes, A.C.D. Rodas, N.B. Lima, O.Z. Higa, I. Costa, Study of the corrosion resistance and in vitro biocompatibility of PVD TiCN-coated AISI 316L stainless steel for orthopedic applications, Surface and Coatings Technology 205 (2010) 2074-2081.

[15] X. Tang, Y. Wu, Y. Yao, Z. Zhang, Effect of temperature and H2S concentration on corrosion of X52 pipeline steel in acidic solutions, Materials Science Forum 743-744 (2013) 589-596.

[16] Y. Xiang, Z. Wang, Z. Li, W.D. Ni, Effect of temperature on corrosion behavior of X70 steel in high pressure $\mathrm{CO}_{2} / \mathrm{SO}_{2} / \mathrm{O}_{2} / \mathrm{H}_{2} \mathrm{O}$ environments, Corrosion Engineering, Science and Technology 48 (2013) 121-129. 